\title{
Transport Costs and the Geography of Arbitrage in Eighteenth-Century China
}

\author{
By CAROL H. ShiUE*
}

Trade has been considered a condition for growth and development, a view that might have merits in explaining the rise of the Western world. I use a new data set from archival sources of eighteenth-century China to revisit this question. This analysis suggests previous studies of market integration, which attribute much growth to a reduction in transport costs, have overestimated these effects. I find the overall level of market integration in China was higher than previously thought, and, intertemporal effects are important substitutes for trade. Both factors reduce the importance of trade as a unique explanation for subsequent growth. (JEL O13, O18, R11, N25)

It is generally agreed that the progressive reduction in transport costs was a major factor in the growth of the United States and Europe. According to Douglas North (1958, p. 537).

Revolutionary developments in transport have been an essential feature of the rapid growth of the Western world of the past two centuries. Reduction in the cost of carriage has enabled specialization and division of labor on a national and international basis to replace the relatively self-sufficient economies that predominated in the Western world two centuries ago.

Lower shipping costs promoted greater production in the newly integrated markets with $e x$ ante lower prices, leading to more trade and overall economic growth. In the United States, railroads, steamboats, and canals each helped transform inland backwoods into agricultural centers (George Rogers Taylor, 1951), and improvements in transport also contributed to the formation of a national labor market (Robert A.

\footnotetext{
* Department of Economics, University of Texas, Austin, TX 78712. I thank Loren Brandt, Robert Evenson, Don Fullerton, Timothy Guinnane, Daniel Hamermesh, James Harrigan, Wolfgang Keller, Preston McAfee, Angelo Melino, Kenneth Pomeranz, T. N. Srinivasan, Maxwell Stinchcombe, and an anonymous referee for helpful comments and suggestions.
}

Margo, 2000). In Europe, the beginning of modern economic growth concurred with the ability of trade to spread shocks over a wide area, thereby reducing their detrimental effect on any one region (Andrew B. Appleby, 1979; Donald McCloskey and John Nash, 1984).

This paper considers whether access to commodity markets is a precondition for market development and economic growth in a newly created data set that covers more than half of the eighteenth-century Chinese economy. With high costs of transport within many provinces, China provides an opportunity to test the relationship between commodity trade and market development. By examining the extent of market integration in a pre-industrial economy that did not also grow substantially in the eighteenth and nineteenth centuries, rather than focusing on economies that succeeded to grow relatively fast, one may obtain a clearer view of the role of commodity trade.

The implications are important not only from the viewpoint of economic history, but also for understanding structural change and economic growth. A finding of, for instance, generally unintegrated markets in China and prices that are largely determined by local shocks would be consistent with the western experience up to the transportation revolution and indicate that China did not grow because there was little interregional trade. This paper, however, challenges that view. My results suggest that even 
though China did not grow as much as economies in the West, a substantial part of China was apparently integrated through trade.

Year-to-year harvest shocks will result in changes in trade flows, grain stocks, and local price shocks, or some combination of these effects. Thus, besides examining trade, which determines only the extent of interregional market integration, ideally one should also examine storage, which sheds light on the extent of intertemporal market integration, as well as the responsiveness of prices to local supply shocks. Based on these observations, this paper draws on previously unpublished archival price lists on grain, historical weather data, distance measurements, and storage records-in order to produce an evaluation of market integration that is as comprehensive as possible.

Price correlations give a view of market integration that has a simple interpretation: the correlation between two markets may be systematically related to the costs of trade between the markets, or systematically related to common supply shocks. The first is evidence of commodity arbitrage, while the second is evidence for the lack thereof. The cost of transport, which determines the scope of trade, is in this paper approximated by distance and regional geography. ${ }^{1}$ In addition, the incorporation of local weather data takes into account common supply relationships that otherwise might be spuriously attributed to trade. The results suggest that regions that did not trade much with other regions were more likely to use storage to smooth the impact of supply shocks, indicating an important role for intertemporal trade in market development.

My findings suggest that the importance of trade to growth has been overestimated. This is seen through two different mechanisms. First, China's markets appear to have been more integrated than previously thought, countering the prevailing wisdom that pre-industrialized economies were self-sufficient until very recently. Second, I show that intertemporal effects are important substitutes for trade, further reducing the sole importance of trade as an explanation

\footnotetext{
${ }^{1}$ See John L. Gallup et al. (2000), e.g., on the relationship between geography and economic development.
}

for growth. Market integration appears to be more of a minor precursor to economic development than a major causal force, and the impact of transport costs is not so much to determine whether or not markets existed, but the types of markets in existence.

\section{Commodity Trade and Transportation in Eighteenth-Century China}

Domestic stability prevailed during the eighteenth century of the Qing dynasty (16441911). Yet, if there were no protracted wars or natural catastrophes, neither were there any notable technological innovations which, individually or collectively, served to radically alter existing production activities or marketing patterns. Foreign trade was largely restricted and rice exports were prohibited. Domestic interregional trade over long distances relied primarily on natural waterways. These major waterways connected numerous cities and provided the lowest cost means of transport available over long distances: the Yangzi River (about 3,500 miles), the Yellow River (over 3,000 miles), and a thousand miles of the Grand Canal extended from major ports south of the mouth of the Yangzi River up to the Beijing area. Including also the tributaries of the Yangzi, the system contained about 30,000 miles of waterway navigable year-round by junk (Laurence Evans, 1984, p. 278). In addition, a certain amount of offshore trading took place along the long coastal stretch between the southern provinces, the Yangzi Delta, and Manchuria.

Estimates of the cost of transport vary, depending on source and method used, but all studies agree that the major division in transport costs was between land and water transportation. Over long distances, junks may have had a 9-10-fold cost advantage over the two primary forms of land transportation, human and animal carriage (Andrew Watson, 1972). Estimates of the volume of trade furthermore suggest the presence of significant trade activity along water routes: some 2.4 million tons of grain moved across provincial borders, a quantity that made up around 40 percent of the value of all commodities traded interregionally (Chengming $\mathrm{Wu}, 1983)$. By the mid-eighteenth century, as much as $10-20$ percent of the grain consumed 
by the large urban population in the Yangzi Delta (of approximately 36 million) was produced outside of the Delta.

Most of these commodities would have been transported by private merchants. Attempts by the Qing government to influence grain supplies through purchases and sales of buffer stocks were on the decline by the mid-eighteenth century. Indeed, the dominance of private traders was imperially acknowledged in 1753, when the Qianlong emperor ruled that government officials were not needed to "manage" the rice trade because private merchants were capable of doing so (Sarasin Viraphol, 1977, pp. 97-98).

Considerably less is known about the inland economy, but the conventional wisdom on the extent of inland trade seems to be that regions with little or no access to water transport must have been economically constrained in proportion to their disadvantage in trade. This view is summarized in Evans (1984, pp. 304-5), and like North's statement on western economies before the transportation revolution, it emphasizes the importance of trade and transport:

Transportation in pre-industrial societies ... places stringent limits on economic activity and absolute limits on the movement of food ... . People could be starving to death in one province while the neighboring province experienced a minor shortage; there would be no way to get food across the few score miles that separated them that did not consume all the food that could be carried.

That less trade took place in remote areas seems certain, but whether this in turn led to the dire consequences that many, including Evans, have suggested, while regions with better access to transport and trade escaped them, is a belief based more on anecdote than on empirical fact. To date, the conventional view remains difficult to confirm, as trade data in inland areas have thus far been neither available nor feasible to estimate. Even if trade volume figures were available, it would still be worth noting that trade volume is an imperfect indicator of integration, regardless of whether that trade takes place over waterways or over land, since mar- kets might be integrated even if observed trade volumes are low.

\section{Price Variation, Weather, and Storage}

Price data can help sharpen existing estimates and inferences about market activity and its capacity to smooth interregional supply shocks, and price and weather data in conjunction can be used to examine the effects of intertemporal shocks. The price data collected during the Qing dynasty are considered to be quite accurate records of purchase prices in a free market (Han-sheng Chuan and Richard A. Kraus, 1975). The price reports contain the highest and lowest prices observed in each prefecture in each lunar month. ${ }^{2}$

The analysis covers ten provinces of Southeast and Central China, an area that includes regions which are historically the most commercial in China (the southern coast, the Yangzi Delta, and the middle Yangzi River region), as well as regions located far away from trading centers. $^{3}$ The ten provinces constitute about 641,390 square miles in land area. Approximately 60 percent of the total population of China, or 120 million people, resided in this area as of 1750 , a figure roughly equal to 15 percent of world population at the time (John D. Durand, 1967, p. 137). The years under analysis span 1742-1795, and 121 prefectures are examined. Within each prefecture, the highest and lowest prices over a given year are highly correlated, and their variances are very close. In my analysis below, I use the average [(highest + lowest)/2] price in the second month and the eighth month, according to a lunar calendar.

The coefficient of variation is often used to summarize price variability from harvest to harvest. The annual coefficient of variation, taken at 20-year intervals for all prefectures and averaged, is equal to 0.12 , with a maximum of 0.17 for the entire sample. Selecting the one prefecture from each of the ten provinces with the maximum coefficient of variation, and av-

\footnotetext{
${ }^{2}$ Gongzhong liangjia qingdan (Grain price lists in the palace archives), Number One Historical Archives, Beijing.

${ }^{3}$ The provinces are Anhwei, Fujian, Guangdong, Guangxi, Guizhou, Hubei, Hunan, Jiangsu, Jiangxi, and Zhejiang.
} 
eraging, gives a value of 0.24 . These figures are similar to the coefficient of variation on wheat prices taken at 20-year intervals in southern England for the years $1800-1825(0.26)$, or in New York for 1825-1914 (0.16-0.34), and lower than those in England from 1245-1350 (0.20-0.43) (McCloskey and Nash, 1984).

The weather data is an index, with five gradations, that summarizes the degree of aridity versus wetness for each year, in each prefecture (State Meteorological Society, 1981). The mean is centered on normal or "good" weather conditions, and deviations from the mean in either direction represent worse conditions. It is a notable characteristic of Chinese historical weather records is that weather is rated relative to normal conditions and crop requirements specific to locale (Peiyuan Zhang, 1993). As a proxy for supply conditions, this is preferable to a measurement of weather along a specific dimension, such as inches of rainfall, since temperature and other factors make the impact of a single objective measure difficult to determine.

Although the most important sources of data on quantities of storage that have emerged thus far are based on various government-mandated granaries, merchants and households would have possessed grain stocks as well. ${ }^{4}$ For all types of stores, the unit cost of grain upkeep (aeration, removal of debris, sunning and turning the grain) would have been affected by differences in climate across regions. Stored grain should be kept dry and cool, and storage costs may have varied considerably across regions if overall climates differed very much. In particular, if a region's humidity is coincident with its proximity to waterways, this would be especially problematic for the identification of trade versus storage effects. Contemporary meteorological measurements of humidity, however, indicate this is not the case. ${ }^{5}$ Moreover,

\footnotetext{
${ }^{4}$ See, for example, Watson's (1972) survey about shipping brokerage firms, where the junk is referred to as "floating warehouses" (p. 25). Anecdotal evidence also points to household storage.

${ }^{5}$ Modern meteorological indices of humidity employ the ratio between temperature and precipitation. The distribution of humidity for most of China ranges from 0.5 (most humid) to 5 (least humid). All regions in this paper are
}

differences in humidity among prefectures examined in this paper are minor, suggesting no one region possessed a clear comparative advantage in storage, and ceteris paribus differences in storage costs were likely to have been quite small in this sample.

\section{A Benchmark Model of Trade and Storage}

The empirical analysis is guided by the key implications of the simplest model of trade fused with the standard model of storage. Weather shocks are assumed to be exogenous and time-independent. Given stable consumer demand, the market price in each period will reflect the impact of the weather, as well as the cost of trade versus storage. Both traders and storers are assumed to behave as price-takers, and to hold rational expectations based on currently available information on the probability of forthcoming yields and price responses to production shocks. ${ }^{6}$

In every period, storers put grain into storage until the marginal gain from doing so equals its opportunity cost, the value of selling it at the market price. In a competitive equilibrium, arbitrage profits do not arise: if selling the grain at the discounted expected price for the next period would more than compensate for the cost of storing it through to the next period, then storers would buy up grain now and drive up the current price until potential arbitrage profits go to zero. The argument is analogous for the case when the discounted expected price falls short of the storage cost. Let $P_{t}$ and $S_{t}$ be the price and amount of storage at time $t$, respectively, let $r$ be the rate of interest, and let $k$ be the constant per unit cost of storage. Then,

$$
P_{t}+k-\frac{E_{t}\left[P_{t+1}\right]}{1+r}=0 \text { for } S_{t}>0
$$

considered "relatively humid" by Chinese meteorologists, that is, 1.0 or less. (Mei'e Ren et al., 1992, p. 76.)

${ }^{6}$ See Jeffrey C. Williams and Brian D. Wright (1991) for more details on a model such as this.

${ }^{7}$ Although specific information on the form of storage costs in the eighteenth century is not available, Williams and Wright (1991, p. 8) suggest that unit costs are roughly constant for all levels of stocks for nonperishable commodities such as grain. 


$$
P_{t}+k-\frac{E_{t}\left[P_{t+1}\right]}{1+r} \geq 0 \text { for } S_{t}=0 \text {. }
$$

When trade is feasible, the intratemporal smoothing of harvest fluctuations across regions is possible along with the intertemporal smoothing accomplished with storage. Let $Z_{t}$ be the net quantity shipped from economy $a$ to $b$, and let $z$ be the constant per-unit costs of shipping. Transport costs drive a wedge between prices in the two economies. In equilibrium, $P_{t}^{a}+z=$ $P_{t}^{b}$ if $Z_{t}>0 ; P_{t}^{a}-z=P_{t}^{b}$ if $Z_{t}<0$; and $\left|P_{t}^{a}-P_{t}^{b}\right| \leq z$ if $Z_{t}=0$. Since there is no reason to transfer grain from one region to another unless there is price gap, trade would not occur between two identical regions that experience identical weather shocks. ${ }^{8}$

With the possibility of trade, the storage decision no longer depends exclusively on local variables. For example, if the price in region $b$, $P_{t}^{b}$, is greater than the price in region $a$ in period $t$ plus cost of storage and transport to $b$ in period $t+1$, then interregional arbitrage opportunities appear. So long as prices in $b$ at $t$ are lower than this threshold, then no trade arises between the two regions, and $b$ stores grain locally. Thus, if region $b$ stores, then it must be that the price in $b$ is less than the present discounted value of storing in region $a$ and shipping to $b$ in the following period:

$$
P_{t}^{b}<\frac{\left(P_{t}^{a}+k\right)(1+r)+z}{(1+r)}-k
$$

or equivalently,

$$
P_{t}^{b}<P_{t}^{a}+\frac{z}{(1+r)}
$$

An analogous expression holds for region $a$.

Storage is an activity that transfers goods in only one direction, to the future, while shipping can transfer goods in either direction between two regions. Trade and storage are nonetheless

\footnotetext{
${ }^{8}$ These equilibrium conditions assume that expectations correctly forecast future prices and there are no fixed costs to arbitrage. The empirical analysis below does not rely on that; in Section IV, subsection A, I also allow for heterogeneity in price levels, for arbitrage gaps, and for price trends.
}

substitutes in the sense that both regions store only in the range where

$$
P_{t}^{a}+\frac{z}{(1+r)}>P_{t}^{b}>P_{t}^{a}-\frac{z}{(1+r)}
$$

which is a subset of the range with no trade, that is, where $P_{t}^{a}+z>P_{t}^{b}>P_{t}^{a}-z$. When trade does take place, it is moreover profitable only for the exporting region (the region with the lower price) to store; it is not profitable for the importing region to store. Similar arguments can be developed to allow for more than two regions where the underlying motivation for trading or storing remains that of attempting to reduce price fluctuations brought about through supply shocks.

\section{Empirical Results}

\section{A. Interregional Market Integration and Common Weather Shocks}

Since waterway access was the chief means by which goods could be shipped at lower costs, ceteris paribus we would expect higher price comovements among prefectures as we move from those that are further away from waterways to prefectures that are closer to waterways. Furthermore, we would expect that the distance between markets determines the extent of trade not only across groups of prefectures, but within each group as well.

I test for evidence of systematic patterns in price correlation across regions that are most likely to trade by using an a priori grouping of prefectures that is based on an objective criterion of transport costs. The sample of 121 prefectures is classified into four regional groups according to their respective distance to a major waterway, where a "major waterway" is defined to be either a major "river" (the Yangzi River and the Grand Canal), or the coast (along the South China Sea and along the East China Sea).

- Group 1-River region: prefectures where the capital is no more than $250 \mathrm{~km}$ from a major river (34 prefectures).

- Group 2-Coastal region: prefectures along the coast. Includes nine prefectures along the 
Table 1 -Summary Statistics

\begin{tabular}{llrrrr}
\hline \hline \multirow{2}{*}{ Group } & \multicolumn{1}{c}{ Variable } & Mean & $\begin{array}{c}\text { Standard } \\
\text { deviation }\end{array}$ & Minimum & Maximum \\
\hline River & price correlation & 0.66 & 0.13 & 0.24 & 0.96 \\
$\quad$ (561 observations) & bilateral distance & 448 & 291 & 13 & 1804 \\
& weather correlation & 0.15 & 0.24 & -0.36 & 1.0 \\
Coast & price correlation & 0.39 & 0.24 & -0.28 & 0.90 \\
(378 observations) & bilateral distance & 787 & 529 & 13 & 2486 \\
& weather correlation & 0.18 & 0.27 & -0.31 & 1.0 \\
Semi-inland & price correlation & 0.35 & 0.28 & -0.43 & 0.90 \\
(561 observations) & bilateral distance & 684 & 337 & 39 & 1563 \\
& weather correlation & 0.06 & 0.21 & -0.59 & 1.0 \\
Inland & price correlation & 0.23 & 0.29 & -0.42 & 0.91 \\
(561 observations) & bilateral distance & 485 & 271 & 25 & 1301 \\
& weather correlation & 0.18 & 0.26 & -0.38 & 1.0 \\
\hline
\end{tabular}

coast situated at the mouth of the Yangzi River and also in Group (1) (28 prefectures).

- Group 3-Semi-inland regions: prefectures next to Group (1) and (2), with capitals located outside a zone of approximately 50-75 kilometers from those boundaries (34 prefectures).

- Group 4-Inland regions: prefectures for which the prefectural capital lies approximately 150 kilometers or more from the nearest boundary of Group (1) and (2) (34 prefectures).

Inland regions would not have had direct access to any of the major water routes, while a majority of semi-inland areas would have been able to access various tributaries of the Yangzi River and rivers feeding into the southern coast. ${ }^{9}$ Few of the inland prefectures would have been able to access the secondary rivers easily. The choice of the threshold distances is an objective, albeit arbitrary, indicator of transport costs. I have therefore confirmed, by choosing alternative thresholds, that the central results below are not sensitive to my specific choice.

Summary statistics for the individual groups on (i) the bilateral correlation coefficient of prices, in the eighth lunar month, (ii) the bilat-

\footnotetext{
${ }^{9}$ These secondary rivers would include the Yuan, Xiang, Huai, Gan, and Xi River(s), the extended reaches of which were navigable only by smaller boats.
}

eral distance ${ }^{10}$ between the prefectures, in kilometers, and (iii) the bilateral correlation coefficient for weather are shown in Table 1.

Table 2 reports benchmark estimates where bilateral relationships are examined within each group. Panel I shows ordinary least-squares (OLS) regressions of price correlation (PC) on weather correlation (WC) and bilateral distance $(D)$. Price correlations are decreasing with distance for all regions. Comparing the point estimates on distance across groups, however, indicates that distance has a larger impact on trade in inland areas than in regions with waterway access. The coefficient on the WC variable tends to be positive, which underlines that common supply shocks could be an important source of price correlations that should be controlled for.

There might be differences across groups that affect price correlations beyond transport and storage costs-for instance, fixed (sunk) trade costs or forecasting techniques might vary. Moreover, these variables could change over time. I have therefore redone the analysis with an alternative price series in which prefecturespecific price levels and a time trend are eliminated. Panel II of Table 2 shows that as we

\footnotetext{
${ }^{10}$ The great-circle distance is calculated from points of latitude and longitude (drawn from George Macdonald Home Playfair, 1965) of prefectural capital cities' historical locations using the "Haversine Formula." Details on the distance figures are in a Data Appendix available from the author upon request.
} 
Table 2-Bilateral Price Correlation in Relation to Distance and

Weather Correlation (REgression: $\mathrm{PC}_{i, j}=\alpha+\beta D_{i, j}+\gamma \mathrm{WC}_{i, j}+v_{i, j}$ )

\begin{tabular}{|c|c|c|c|c|}
\hline Variable & $\begin{array}{c}\text { River } \\
\text { prefectures } \\
\text { (1) }\end{array}$ & $\begin{array}{c}\text { Coastal } \\
\text { prefectures } \\
(2)\end{array}$ & $\begin{array}{l}\text { Semi-inland } \\
\text { prefectures } \\
\text { (3) }\end{array}$ & $\begin{array}{c}\text { Inland } \\
\text { prefectures } \\
\text { (4) }\end{array}$ \\
\hline \multicolumn{5}{|l|}{ Panel I: } \\
\hline Distance & $\begin{array}{c}-0.155^{*} \\
(0.018)\end{array}$ & $\begin{array}{c}-0.195 * \\
(0.022)\end{array}$ & $\begin{array}{r}-0.326 * \\
(0.032)\end{array}$ & $\begin{array}{c}-0.393 * \\
(0.043)\end{array}$ \\
\hline Weather & $\begin{array}{c}0.120 * \\
(0.023)\end{array}$ & $\begin{array}{c}0.266^{*} \\
(0.036)\end{array}$ & $\begin{array}{r}-0.026 \\
(0.050)\end{array}$ & $\begin{array}{c}0.147^{*} \\
(0.047)\end{array}$ \\
\hline Constant & $\begin{array}{l}0.715^{*} \\
(0.011)\end{array}$ & $\begin{array}{l}0.511 * \\
(0.021)\end{array}$ & $\begin{array}{c}0.577 * \\
(0.024)\end{array}$ & $\begin{array}{l}0.389 * \\
(0.031)\end{array}$ \\
\hline $\begin{array}{l}\text { Number of observations } \\
R^{2}\end{array}$ & $\begin{array}{r}561 \\
0.24\end{array}$ & $\begin{array}{r}378 \\
0.42\end{array}$ & $\begin{array}{l}561 \\
0.15\end{array}$ & $\begin{array}{c}561 \\
0.19\end{array}$ \\
\hline \multicolumn{5}{|l|}{ Panel II: } \\
\hline Distance & $\begin{array}{c}-0.193 * \\
(0.022)\end{array}$ & $\begin{array}{r}-0.226^{*} \\
(0.023)\end{array}$ & $\begin{array}{r}-0.293 * \\
(0.031)\end{array}$ & $\begin{array}{c}-0.523^{*} \\
(0.036)\end{array}$ \\
\hline Weather & $\begin{array}{l}0.147 * \\
(0.031)\end{array}$ & $\begin{array}{c}0.394 * \\
(0.043)\end{array}$ & $\begin{array}{c}0.101 * \\
(0.047)\end{array}$ & $\begin{array}{l}0.233 * \\
(0.034)\end{array}$ \\
\hline Constant & $\begin{array}{l}0.631 * \\
(0.014)\end{array}$ & $\begin{array}{l}0.362 * \\
(0.027)\end{array}$ & $\begin{array}{l}0.432 * \\
(0.024)\end{array}$ & $\begin{array}{l}0.545^{*} \\
(0.025)\end{array}$ \\
\hline $\begin{array}{l}\text { Number of observations } \\
R^{2}\end{array}$ & $\begin{array}{r}561 \\
0.24\end{array}$ & $\begin{array}{r}378 \\
0.51\end{array}$ & $\begin{array}{l}561 \\
0.15\end{array}$ & $\begin{array}{c}561 \\
0.40\end{array}$ \\
\hline Panel IIIa: & {$[\leq 1100 \mathrm{~km}]$} & {$[\leq 1500 \mathrm{~km}]$} & {$[\leq 1100 \mathrm{~km}]$} & {$[\leq 800 \mathrm{~km}]$} \\
\hline Distance & $\begin{array}{c}-0.228 * \\
(0.024)\end{array}$ & $\begin{array}{c}-0.272 * \\
(0.024)\end{array}$ & $\begin{array}{c}-0.452 * \\
(0.044)\end{array}$ & $\begin{array}{c}-0.597 * \\
(0.075)\end{array}$ \\
\hline Weather & $\begin{array}{c}0.086^{*} \\
(0.024)\end{array}$ & $\begin{array}{c}0.259^{*} \\
(0.037)\end{array}$ & $\begin{array}{r}-0.069 \\
(0.050)\end{array}$ & $\begin{array}{c}0.0823^{\dagger} \\
(0.052)\end{array}$ \\
\hline Constant & $\begin{array}{c}0.747 * \\
(0.013)\end{array}$ & $\begin{array}{c}0.553 * \\
(0.021)\end{array}$ & $\begin{array}{c}0.645^{*} \\
(0.0283)\end{array}$ & $\begin{array}{c}0.477 * \\
(0.042)\end{array}$ \\
\hline $\begin{array}{l}\text { Number of observations } \\
R^{2}\end{array}$ & $\begin{array}{r}542 \\
0.26\end{array}$ & $\begin{array}{r}338 \\
0.45\end{array}$ & $\begin{array}{c}487 \\
0.17\end{array}$ & $\begin{array}{c}484 \\
0.18\end{array}$ \\
\hline Panel IIIb: & {$[>1100 \mathrm{~km}]$} & {$[>1500 \mathrm{~km}]$} & {$[>1100 \mathrm{~km}]$} & {$[>800 \mathrm{~km}]$} \\
\hline Distance & $\begin{array}{r}-0.238^{\dagger} \\
(0.136)\end{array}$ & $\begin{array}{c}0.135 * \\
(0.053)\end{array}$ & $\begin{array}{c}0.309^{\dagger} \\
(0.185)\end{array}$ & $\begin{array}{r}-0.106 \\
(0.137)\end{array}$ \\
\hline Weather & $\begin{array}{c}0.054 \\
(0.190)\end{array}$ & $\begin{array}{r}-0.011 \\
(0.030)\end{array}$ & $\begin{array}{c}0.406^{\dagger} \\
(0.247)\end{array}$ & $\begin{array}{c}0.211 \\
(0.190)\end{array}$ \\
\hline Constant & $\begin{array}{c}0.920 * \\
(0.189)\end{array}$ & $\begin{array}{r}-0.026 \\
(0.113)\end{array}$ & $\begin{array}{r}-0.192 \\
(0.243)\end{array}$ & $\begin{array}{c}0.149 \\
(0.141)\end{array}$ \\
\hline Number of observations & 19 & 40 & 74 & 77 \\
\hline$R^{2}$ & 0.19 & 0.10 & 0.08 & 0.03 \\
\hline
\end{tabular}

Notes: Distance in units of 1,000 km. Heteroskedasticity-consistent (Halbert White, 1980) standard errors are in parentheses in Panels I and II. Bootstrapped standard errors (Bradley Efron, 1982) are reported in parentheses in Panels IIIa and IIIb. Threshold distances for Panels IIIa and IIIb are in square brackets. See text for further explanation.

Significantly different from zero at the 10-percent level.

* Significantly different from zero at the 5-percent level.

move across groups, the results are qualitatively the same as with the benchmark series: conditional on weather correlation, a one-kilometer increase in distance among inland prefectures is associated with a two to three times as large a reduction of price correlation as in the river region. While the influence of group-specific unobserved heterogeneity continues to be a con- 
cern, Panel II of Table 2 suggests that their importance for these results is limited.

The functional form assumed with the OLS specification-linearity-is a strong parametric assumption that might not hold. I have therefore also estimated nonparametric locally weighted and kernel regression models, including William S. Cleveland's (1979) method. ${ }^{11}$ For both the bivariate $(\mathrm{PC} ; D)$ as well as the multivariate (PC; $D$; WC) analysis, the results broadly confirm the OLS results. However, especially for the semi-inland and inland regions, there appears to be a critical distance beyond which a further increase in distance has a smaller or an insignificant effect on price correlation. This is consistent with entering a "no-trade" distance range.

The regressions in Panel III use the data of Panel I, but allow for a spline within each group of prefectures at these critical distances. This is about $800 \mathrm{~km}$ for inland, $1,100 \mathrm{~km}$ for river and semi-inland, and $1,500 \mathrm{~km}$ for coastal regions. These values are chosen after inspecting the raw-data scatterplots, and are very close to the thresholds attained by minimizing an overall sum-of-squares criterion. ${ }^{12}$ Here, the inferences are based on bootstrapping techniques (Efron, 1982) with 1,000 replications each. Notably, when distances are larger than the threshold distances (Panel IIIb), price correlation and distance are generally not significantly related anymore or of the wrong sign. By contrast, for all groups, the benchmark results are still confirmed in the low-distance subsample (Panel IIIa). The estimated confidence intervals of Panel IIIa are also not very different from Panels I or II. In addition, I performed regressions based on other specifications (not reported), including the logarithmic and adding polynomial terms, but the results were qualitatively the same.

Overall, the similar results across different specifications suggest that the qualitative findings of the benchmark case are robust.

\footnotetext{
${ }^{11}$ As implemented in statistical packages such as S-Plus and Stata. These results are available from the author upon request.

${ }^{12}$ Note, however, that the "high distance" samples for the river and coastal groups are relatively small.
}

\section{B. Intertemporal Market Integration}

This subsection examines whether there is a significant difference in the response of price to local weather shocks as we move across groups of prefectures. Specifically, I ask whether regions that did not have immediate waterway access (semi-inland and inland prefectures), and which apparently had more limited means of using trade to spread production shocks, were therefore more susceptible to price variations as a result of fluctuations in the local harvest.

A simple way of examining this is in an OLS regression of price on weather and regional interaction terms. Variations in supply are unlikely to have a strong impact on prices either in the current year or in subsequent years if storage from harvest to harvest was typically large enough to absorb these shocks. However, if prices from year to year move with close association to weather patterns, storage opportunities are likely to have been small. Table 3 shows the estimated relationships between $P_{t}$, the mean price recorded in the eighth lunar month in each prefecture across the years 1742-1795, and $Q_{j, t}$, the current year $t$ weather in prefecture $j$, and $Q_{j, t-1}$, last year's weather. $Q_{j, t-1}^{*}$ is a fixed effect for the worst years of weather. ${ }^{13} R$ is a fixed effect for the river and coastal prefectures, and Year is an annual time trend.

Column (1) shows the results for all prefectures. ${ }^{14}$ The positive coefficient on the weather variables is consistent with worse weather being associated with higher prices. Prices are affected by weather in the current, as well as in the previous year. The worst weather shocks are significant at the 10-percent level, but not at the 5 -percent level $(\delta=0.023)$. The results in column (2) allow for differences between the river and coastal, versus the semi-inland and inland prefectures. The response of prices to last year's weather, in the "semi-inland and inland" and the "river and coastal" prefectures, is given

\footnotetext{
${ }^{13}$ The variable $Q$ takes values equal to 1,2 , and 3, defined as good, fair, and foul, respectively. The worst weather shocks corresponds to $Q=3$. On average, the weather in 47 percent of the years was good, 43 percent fair, and 10 percent foul.

${ }^{14}$ Observations with missing data in any one variable were dropped ( 24 percent of sample).
} 
Table 3-Relationship Between Local Price and Weather:

Difference BetweEn River/Coast vs. Semi-inland/InLANd Prefectures

(REGRESSION: $\ln P_{j, t}=\alpha+\phi^{0} \ln Q_{j, t}+\gamma^{0} \ln Q_{j, t-1}+\delta Q_{j, t-1}^{*}+$ Year $_{t}+\beta R$ $\left.+\left(\phi^{1}-\phi^{0}\right) R \ln Q_{j, t}+\left(\gamma^{1}-\gamma^{0}\right) R \ln Q_{j, t-1}+\theta R Q_{j, t-1}^{*}+\varepsilon_{j, t}\right)$

\begin{tabular}{lcccc}
\hline \hline Independent variable & $(1)$ & $(2)$ & $(3)$ & $(4)$ \\
\hline$\phi^{0}$ & $0.115^{*}$ & $0.111^{*}$ & $0.111^{*}$ & $0.105^{*}$ \\
& $(0.009)$ & $(0.013)$ & $(0.008)$ & $(0.011)$ \\
$\gamma^{0}$ & $0.110^{*}$ & $0.122^{*}$ & $0.108^{*}$ & $0.118^{*}$ \\
$\delta$ & $(0.010)$ & $(0.013)$ & $(0.010)$ & $(0.013)$ \\
& $0.023^{\dagger}$ & -0.004 & 0.017 & -0.012 \\
Trend & $(0.014)$ & $(0.019)$ & $(0.013)$ & $(0.019)$ \\
& & & $0.003^{*}$ & $0.003^{*}$ \\
$\beta$ & & $0.229^{*}$ & $(0.0002)$ & $(0.0002)$ \\
& & $(0.010)$ & & $0.224^{*}$ \\
$\left.\phi^{1}-\phi^{0}\right)$ & & $-0.050^{*}$ & & $(0.010)$ \\
& & $(0.016)$ & & $-0.045^{*}$ \\
$\left.\gamma^{1}-\gamma^{0}\right)$ & & $-0.093^{*}$ & & $(0.152)$ \\
$\theta$ & & $(0.018)$ & & $-0.087^{*}$ \\
& & $0.071^{*}$ & & $0.017)$ \\
Constant & $(0.025)$ & & $0.072^{*}$ \\
& & $0.133^{*}$ & $-5.75^{*}$ & $-5.72^{*}$ \\
Number of observations & 4,945 & 4,945 & 4,945 & $(0.389)$ \\
Adjusted $R^{2}$ & 0.09 & 0.22 & 0.13 & 0.2645 \\
\hline
\end{tabular}

Note: Heteroskedasticity-consistent (White, 1980) standard errors are in parentheses. See text for further explanation.

Significantly different from zero at the 10-percent level.

* Significantly different from zero at the 5-percent level.

by $\gamma^{0}(=0.122)$ and $\gamma^{1}(=0.029)$, respectively. Compared to the prefectures further from waterways, prefectures close to waterways appear to overcome the effects of last year's supply fluctuations more easily. This suggests that in general, in the river and coastal prefectures, the lagged effects of supply changes are dissipated more rapidly, and do not affect prices very much.

However, after an unusually bad shock, prices are significantly higher this year in the river and coastal regions, while the same effect is comparatively weak in semi-inland and inland regions. This is indicated by the coefficient, $\delta$, on the worst harvest shock, which is -0.004 (not statistically different from zero at the 10-percent level) in semi-inland and inland prefectures, while the corresponding coefficient, $\theta+\delta$, in river and coastal is 0.067 . This suggests that semi-inland and inland prefectures are able to withstand the effects of severe sup- ply shocks in the preceding year better than river and coastal regions. ${ }^{15}$

The main results are robust to the inclusion of a time trend. Those coefficients are reported in columns (3) and (4). I have also experimented with other and, in particular, less parametric methods, and the qualitatively findings are very similar. Thus, while river and coastal regions have an advantage in trade, these results are consistent with semi-inland and inland regions having a comparative advantage in storage to

\footnotetext{
${ }^{15}$ This intertemporal stability in prices in the more inland regions does not appear to arise from regional supply stability: the null hypothesis that annual weather is independently and identically distributed within all regions cannot be rejected (at the 95-percent significance level) and weather did not change significantly within any region over the sample period. More details on weather are in an Appendix available from the author upon request.
} 


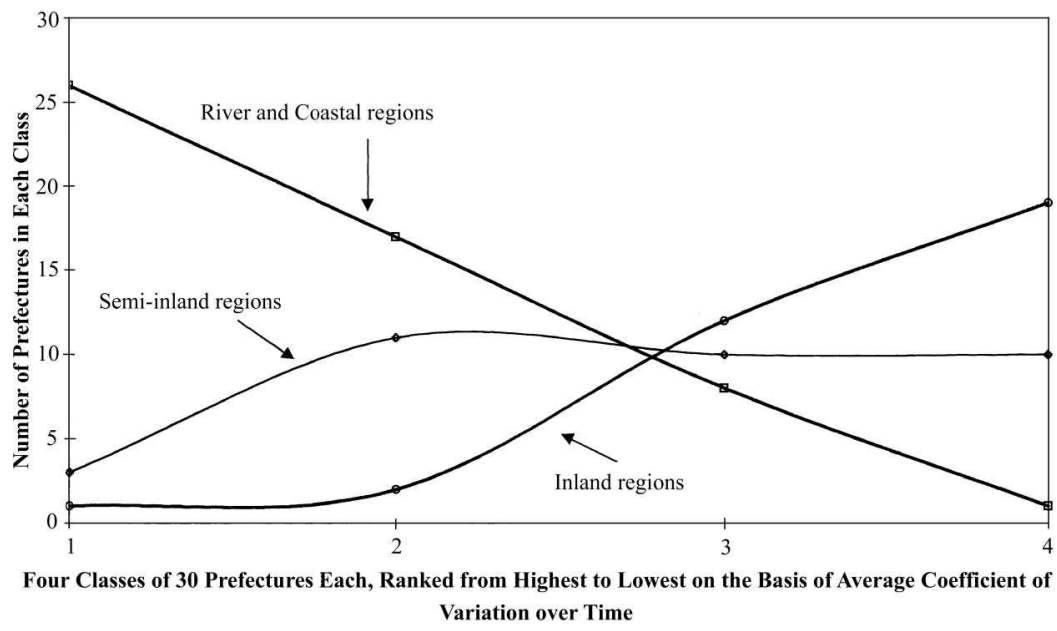

Figure 1. Price Variation from Year to Year: Coefficient of Variation by Type of Region

cushion the effects of worst-weather supply shocks.

\section{Carryover from Harvest to Harvest Versus Carryover Within the Harvest Year}

The results from the previous subsection indicate that storage might have taken place in regions where markets were not interregionally integrated. An implication of the benchmark model of trade and storage, however, is not only that there is storage, but that storage should be higher in equilibrium in the range where there is "no trade." This subsection compares how the price response differs as one moves from relatively more interregionally integrated regions to relatively less interregionally integrated regions.

Figure 1 shows how prefectures in each regional group rank according to the coefficient of variation. All prefectures in the sample were ranked from highest to lowest according to their average coefficients of variation, and the ranking was further divided into four classes, with 1 being the highest and 4 the lowest. Then, within each class of 30 prefectures, the number of prefectures that fall into each of the geographic groups are counted. ${ }^{16}$ A clear pattern emerges: from harvest to harvest, prices fluctuate less as

\footnotetext{
${ }^{16}$ The 61 st prefecture was arbitrarily removed to obtain four classes with an equal number of prefectures in each.
}

one moves from prefectures closer to waterways to those further inland. Although trading regions appear to be interregionally integrated, there is relatively little evidence of intertemporal trade. Moreover, not only are inland regions less vulnerable than trading regions to price fluctuations caused by severe harvest shocks, but their intertemporal prices are in fact more stable than those in regions which do trade.

A corresponding analysis may be made with respect to within-year price fluctuations. ${ }^{17}$ The average rate of increase in monthly prices serves as a measure of the carrying cost of storage $k$, or, the interest that could be earned in alternative investments: $(1+r)=E_{t}\left[P_{t+1}\right] /$ $\left(P_{t}+k\right)$. If storers have rational expectations about the forward price, then the price of grain rises at the same rate as the carrying cost, the sum of the cost of storing a unit of grain plus spoilage plus the opportunity cost of forgone interest. The grain in storage from January to February, for instance, must in equilibrium earn its total carrying cost in order for storage to take place. Otherwise, storage would fall, and prices in February would then rise to the point where the monthly increase in price is equal to the carrying cost. The advent of the new harvest

\footnotetext{
${ }^{17}$ An argument following McCloskey and Nash (1984).
} 


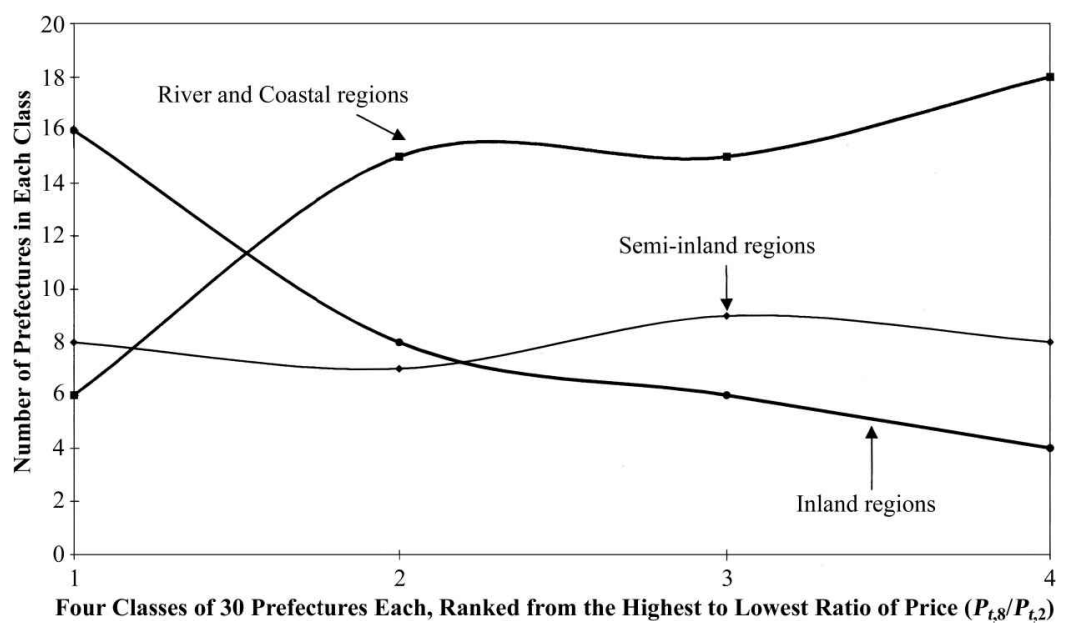

Figure 2. Price Variation Within a Given Year: High-to-Low Price Ratio by Type of Region

causes producers and storers to recalculate the allocation of yields.

This relationship can be analyzed by considering a span of time after the old harvest but prior to the new harvest. ${ }^{18}$ The average "slope" of prices within the harvest year is estimated by dividing the rice prices from the eighth lunar month (which generally falls in July or August in the solar calendar) by the rice prices in the second lunar month (January or February): $P_{t, 8} / P_{t, 2}$.

Figure 2 depicts the slope of prices in ranked classes from highest (1) to lowest (4) within each of the geographical groups. The procedure is similar to that underlying Figure 1, except that intrayear prices are examined. Within the harvest year, prices fluctuate more as one moves from prefectures closer to waterways to those further inland. In contrast to the inland regions, where storage yields intertemporal smoothing and higher price stability, river and coastal regions are more effective at the contemporaneous smoothing of harvest fluctuations, even though the trading network as a whole experi-

\footnotetext{
18 Although cropping patterns do differ across provinces, the fall crop remains the most important crop for all regions considered here (Chuan and Kraus, 1975). Moreover, the average rate of change in prices between single-cropping (1.12) and multiple-cropping provinces (1.14) over the same six-month period are similar.
}

ences higher year-to-year variability in price. Thus, this result also supports the view that the mechanism regions use to stabilize harvest fluctuations is related to differences in the degree of access to transportation and trade.

\section{Storage Patterns Across Prefectures}

The analysis so far suggests that alternative methods of consumption smoothing were in place. To some extent, this can be corroborated with the storage data on public grain stocks that are recorded in local gazetteers. While the qualifications of these data should be noted (Pierre-Etienne Will, 1985; Shiue, 2002), local gazetteers are the only source for subprovinciallevel information on granaries available at this time.

I have compiled data on storage in the prefectures of four provinces: Guangdong, Guangxi, Hunan, and Hubei. Figure 3 shows the amounts of grain stored in the prefectures in these provinces by geographical group, divided by a measure of prefectural population, also recorded in the gazetteers. ${ }^{19}$ Relatively high

\footnotetext{
${ }^{19}$ The population data in the gazetteers is used to approximate the relative population size across regions. As further checks, I have redone the analysis separately for different size/types of granaries, and, also for records that appear to be approximations of stocks (as evidenced by
} 


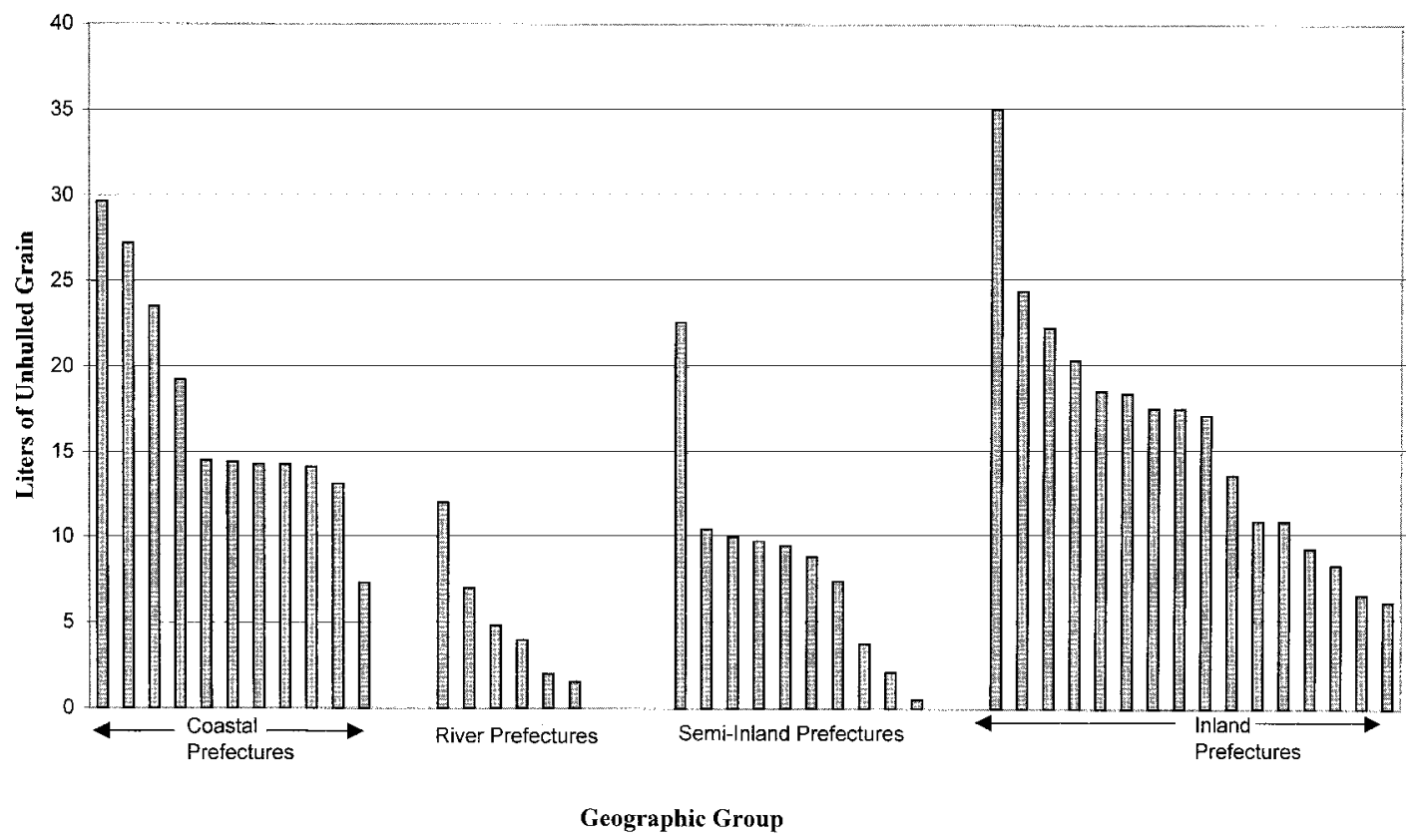

Figure 3. Unhulled Grain per Capita in Public Granaries of Hunan, Guangdong, Hubei, and Guangxi Provinces, Grouped by Geographic Region, Early 1800’s

levels of per capita storage are found in the coastal areas, but the median storage in the sample of inland prefectures is approximately four times the median level for prefectures in the river group. Thus, regional differences in access to interregional trade appear to explain part of the variation in per capita storage across prefectures. In the context of the empirical evidence on price movements from the previous subsections, a plausible interpretation of the overall geographic patterns of grain storage is that they are a product of market-induced incentives and differences in terms of waterway access.

\section{Conclusion}

The evidence presented in this paper points to a substantial level of interregional and intertem-

highly rounded numbers) versus records of actual stocks, but none of these considerations changed the qualitative result of Figure 3. poral market integration in eighteenth-century China, a finding that suggests markets in preindustrial societies may have been more developed than previously acknowledged. The main findings demonstrate that geographic differences could create large differences in the prevailing type of market institutions, but the emergence of markets does not seem to depend on whether or not low transport costs are available. Integrated markets existed even in the absence of low transport costs and much regional trade. While precise comparisons of the extent of this integration with western economies cannot yet be made, the failure to account for storage and other types of markets that substituted for trade would in general lead to an overestimate of the importance of the latter.

This paper is a starting point in the analysis of relative living standards that are determined by exogenous factors and the different economic institutions that are endogenously chosen in response to those factors. The analysis of subsequent growth dynamics is left for future 
research, but clearly, the dichotomy of the relative importance of trade versus storage in response to transport cost differences could well affect long-run development outcomes in the presence of dynamic increasing returns to scale or some other mechanism of feedback. Thus, the present analysis provides some additional information on the determinants of long-run convergence and divergence in per capita incomes more generally.

\section{REFERENCES}

Appleby, Andrew B. "Grain Prices and Subsistence Crisis in England and France: 15901740." Journal of Economic History, December 1979, 39(4), pp. 865-87.

Chuan, Han-sheng and Kraus, Richard A. MidCh'ing rice markets and trade: An essay in price history. Cambridge, MA: Harvard University Press, 1975.

Cleveland, William S. "Robust Locally Weighted Regression and Smoothing Scatterplots." Journal of the American Statistical Association, December 1979, 74(368), pp. 82936.

Durand, John D. "The Modern Expansion of World Population." Proceedings of the American Philosophical Society, June 1967, 111(3), pp. 136-59.

Efron, Bradley. The jackknife, the bootstrap and other resampling plans. Philadelphia: Society for Industrial and Applied Mathematics, 1982.

Evans, Laurence E. "Junks, Rice, and Empire: Civil Logistics and the Mandate from Heaven." Historical Reflections/Réflexions Historiques, Fall 1984, 11(3), pp. 271-313.

Gallup, John L.; Mellinger, Andrew D. and Sachs, Jeffrey D. "Geography and Economic Development," in Gordon L. Clark, Meric S. Gertler, and Maryann P. Feldman, eds., $O x$ ford handbook of economic geography. Oxford: Oxford University Press, 2000, pp. 169-93.

Gongzhong liangjia qingdan (Grain price lists in the palace archives). Beijing: Number One Historical Archives, 1742-1795.

Guangdong tongzhi (Provincial gazetteer of Guangdong Province). Compiled by Ruan Yuan, Chen Changzhai, and Lui Binhua. Uni- versity of Chicago Library Collection, Chicago, IL, 1822.

Guangxi tongzhi (Provincial gazetteer of Guangxi Province). Compiled by Xie Qikun and $\mathrm{Hu}$ Qian. Library of Congress, Washington, DC, 1800.

Hubei tongzhi (Provincial gazetteer of Hubei Province). Compiled by Yang Chenxi. Yale University Library Collection, New Haven, CT, 1911.

Hunan tongzhi (Provincial gazetteer of Hunan Province). Compiled by Weng Yuanqi and Wang Xu. Genealogical Society of Utah, Salt Lake City, UT, 1820.

Margo, Robert A. Wages and labor markets in the United States, 1820-1860. Chicago: University of Chicago Press, 2000.

McCloskey, Donald and Nash, John. "Corn at Interest: The Extent and Cost of Grain Storage in Medieval England." American Economic Review, March 1984, 74(1), pp. 174-87.

North, Douglas. "Ocean Freight Rates and Economic Development 1750-1913.” Journal of Economic History, December 1958, 18(4), pp. 537-55.

Playfair, George Macdonald Home. Cities and towns of China: A geographical dictionary. Taibei, Taiwan: Literature House, Ltd., 1965.

Ren, Mei'e; Yang, Renzhang and Bao, Haosheng. An outline of the physical geography of China. Beijing: Foreign Language Press, 1985.

Shiue, Carol H. "The Public Provision of Disaster Relief in Eighteenth and Nineteenth Century China." Mimeo, University of Texas, 2002.

State Meteorological Society. Zhongguo jin wubai nien hanlao fenbu tuji (Collected maps of droughts and floods in China in the past five hundred years). Beijing: Ditu chuban she, 1981.

Taylor, George Rogers. The transportation revolution: 1815-1860. New York: Holt, Rinehart, and Winston, 1951.

Viraphol, Sarasin. Tribute and profit: SinoSiamese trade, 1652-1853. Cambridge: Harvard University Council on East Asian Studies, 1977.

Watson, Andrew. Transport in transition: The evolution of traditional shipping in China. Ann Arbor, MI: University of Michigan, 1972. 
White, Halbert. "A Heteroskedasticity Consistent Covariance Matrix Estimator and a Direct Test for Heteroskedasticity." Econometrica, May 1980, 48(4), pp. 817-38.

Will, Pierre-Etienne. "Local Gazetteers as a Source for the Study of Long-term Economic Change in China: Opportunities and Problems." Hanxue Yanjiu (Chinese Studies), 1985, 3(2), pp. 707-38.

Williams, Jeffrey C. and Wright, Brian D. Stor- age and commodity markets. New York: Cambridge University Press, 1991.

Wu, Chengming. Zhongguo ziben zhuyi yu guonei shichang (Capitalism in China and the National Market). Beijing: Zhongguo shehui chuban she, 1983.

Zhang, Peiyuan. "Extraction of Climate Information from Chinese Historical Writings." Late Imperial China, December 1993, 14(2), pp. 96-104. 